\title{
Microstructure and mechanical properties of ultra-high strength steel with different cooling process
}

\author{
Yongli Chen \\ The state key laboratory of Rolling and Automation, \\ Northeastern University \\ Shenyang, China \\ Chongqing University of Science and Technology, \\ Chongqing, China \\ Corresponding author: hubeichyl@163.com \\ Xuejiao Zhou \\ Chongqing University of Science and Technology, \\ Chongqing, China
}

\author{
Jianguo Huang \\ The state key laboratory of Rolling and Automation, \\ Northeastern University \\ Shenyang, China \\ Yang Zhao \\ The state key laboratory of Rolling and Automation, \\ Northeastern University \\ Shenyang, China
}

\begin{abstract}
Influences of different colling processes on microstructure transformation and mechanical properties and microstructure of ultra-high strength steels(UHSS) were investigated. microstructure and distribution characteristics were obtained. Samples were proceeded by a controlled rolling (CR) followed by a second step of the direct air cooling (AC), controlled cooling (CC) and direct quenching(DQ), respectively. Experimental results of $\mathrm{CR}+\mathrm{AC}$ process showed that hot rolling microstructure was $0.2-0.3 \mu \mathrm{m}$ slender bamboo-like lath bainitic ferrite. $\mathrm{CR}+\mathrm{CC}$ process acquired higher strength $\sigma 0.2=915 \mathrm{MPa}$, $\sigma b=1640 \mathrm{MPa}$, better tenacity and lower yield ratio $\sigma 0.2 / \sigma b=0.56, \alpha k v=52.13 \mathrm{~J} \cdot \mathrm{cm} 1 / 2$. ductile fracture happened during CR+AC. Multiple rupture mechanisms of quasicleavage and ductile fracture existed in $C R+C C$ process. blockish structure and volume fraction of retained austenite decreased, while carbon content increased compared with $\mathrm{CR}+\mathrm{AC}$ process. The fracture of the alloys was observed to be in quasi-cleavage failure mode during CR+DQ process, blocky structure in retained austenite disappeared basically, volume fraction and carbon content lower than that in $\mathrm{CR}+\mathrm{CC}$ process.
\end{abstract}

Keywords-Ultra-high strength steel; Component design; short flow processes; Microstructure transformation; Residual austenite

\section{INTRODUCTION}

Ultra-high strength steel (UHSS) is widely applied in automotive industry, engineering machinery, mine exploitation, military and aerospace industry due to its excellent performance, such as high strength, strong toughness and good ductility[1-3] . It is reported that the automotive industry currently enjoys the benefits of UHSS with yield strengths of up to $1400 \mathrm{MPa}$ [4]. Wang et al.[5] illuminated that if the tempering temperature was controlled at $250{ }^{\circ} \mathrm{C}$, the maximum yield strength of 1554 $\mathrm{MPa}$ could be reached[6]. However, compared with traditional steel, UHSS has various alloy elements and their contents are higher[7]. Ultra-high strength low alloy steel contains approximately $1.8 \%$ nickel or $1.7 \%$ nickel + chromium+ molybdenum [8]. Therefore, it is difficult to deal with in technology, and it will prolong heat treatment process, which is detrimental to scale production[9]. Designing an appropriate simple composition system, developing a relatively short and flexibility process for production of super-high strength steel becomes a world problem that the domestic and foreign steel rolling enterprises urgently need to solve.

\section{MATERIALS AND EXPERIMENTAL PROCEDURE}

\subsection{MATERIALS}

The test steel was smelt by a $150 \mathrm{~kg}$ vacuum induction furnace in RAL lab. Harmful elements of test steel such as $\mathrm{S}$ and $\mathrm{P}$ were controlled in a strict manner. Its chemical compositions (weight percent) were $0.23 \mathrm{C}$, $1.95 \mathrm{Si}$, 1.95Mn, 0.007P, 0.003S, $\mathrm{Ni}++\mathrm{Cr}+\mathrm{Mo}+\mathrm{Nb}+\mathrm{V} \leq 2.6$.

\subsection{ROLLING PROCEDURE}

To make the full solution of the casting blank alloy elements, it needs high-temperature heating, however, the overtemperature easily causes the $\gamma$ grain to excessively abnormally grow up[10,11]. Moreover, the overlength heat preservation time is likely to cause worse phenomena such as billet surface decarburization, casting billet surface burning loss, even forming widmanstatten structure and brain overburning, etc. Billet is put into the box-type high temperature electric furnace when the furnace temperature rises to $1250{ }^{\circ} \mathrm{C}$, heated and kept temperature for 120 minutes. Subsequently, the billet is taken out of the furnace 
quickly and eliminated the "furmace scale" [12] on the surface by using the mechanically knocking descaling method.

The rolling test is carried out on the two-roll reversible high-rigidity hot rolling mill with a diameter of $450 \mathrm{~mm}$. After rolling, the cooling speed of cooling device can be adjusted steplessly to that of the direct quenching by controlling cooling. The cooling speed is controlled precisely. Portable far-infrared ray thermometer of American Raytek is used to measure the rolling temperature, and it can get the mean temperature after three times measurement. Reduction per pass directly affects recrystallization rate and phase change storage energy in the process of rolling[30], meanwhile, cumulative reduction rate of high temperature recrystallization directly affect the dynamic recrystallization and static recrystallization rate, thus affecting the grain size of original austenite which is not in crystalline region.Researches[13] have shown that the original austenite grain size obviously affects the strength and toughness of phase transition in the $\gamma \rightarrow \alpha$ transition process. It adapts two-stage controlled rolling to get the 12 $\mathrm{mm}$ steel plate. The initial rolling temperature of recrystallization temperature zone is $1150 \sim 1050^{\circ} \mathrm{C}$, and the initial rolling temperature of non-recrystallization zone is
950 900 ${ }^{\circ} \mathrm{C}$. Cooling process after rolling is shown in Figure 1. Each pass reduction rate $: 17 \% \rightarrow 31 \% \rightarrow 31 \% \rightarrow$ $17 \% \rightarrow 23 \% \rightarrow 17 \% \rightarrow 32 \% \rightarrow 8 \%$, and hot rolling experimental parameters are shown in Table 1.

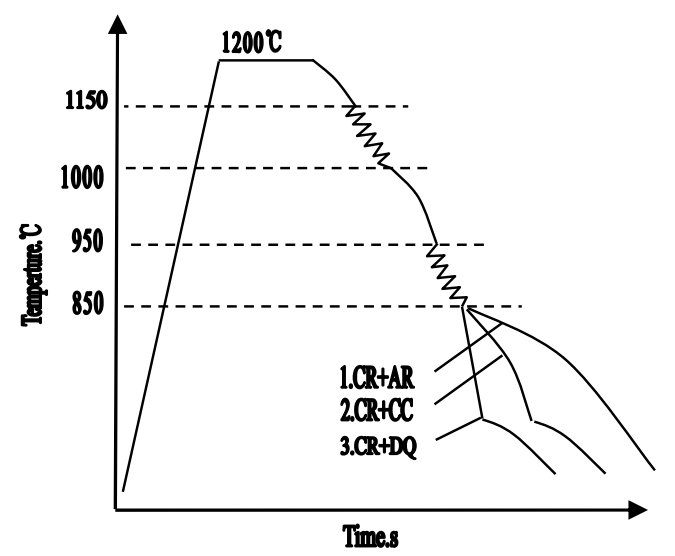

Figure 1. Schematic diagram of different process

TABLE I. THE MEASURED DATA OF PROCESSING PARAMETER OF HOT ROLLING

\begin{tabular}{|c|c|c|c|c|c|c|}
\hline \multirow[b]{3}{*}{ process } & \multicolumn{4}{|c|}{ controlled rolling } & \multirow{2}{*}{\multicolumn{2}{|c|}{ controlled cooling }} \\
\hline & \multicolumn{2}{|c|}{ recrystallization } & \multicolumn{2}{|c|}{ subrecrystallization } & & \\
\hline & $\begin{array}{c}\text { start } \\
\text { temperature } \\
\left({ }^{\circ} \mathrm{C}\right)\end{array}$ & $\begin{array}{c}\text { finish } \\
\text { temperature }\left({ }^{\circ} \mathrm{C}\right)\end{array}$ & $\begin{array}{c}\text { start } \\
\text { temperature } \\
\left({ }^{\circ} \mathrm{C}\right)\end{array}$ & $\begin{array}{c}\text { finish } \\
\text { temperature }\left({ }^{\circ} \mathrm{C}\right)\end{array}$ & $\begin{array}{c}\text { finish } \\
\text { temperature }\left({ }^{\circ} \mathrm{C}\right)\end{array}$ & $\begin{array}{c}\text { cooling rate ( } \\
\left.{ }^{\circ} \mathrm{C} \cdot \mathrm{s}-1\right)\end{array}$ \\
\hline $\mathrm{CR}+\mathrm{AC}$ & 1090 & 1072 & 900 & 885 & - & - \\
\hline $\mathrm{CR}+\mathrm{CC}$ & 1090 & 1073 & 900 & 880 & 303 & 8 \\
\hline $\mathrm{CR}+\mathrm{DQ}$ & 1090 & 1068 & 900 & 890 & 334 & 16 \\
\hline
\end{tabular}

\subsection{MECHANICS PERFORMANCE TEST METHODS}

Microhardness test is performed on the FM-700 hardness testing machine, the load is $100 \mathrm{~g}$, and the load time is $15 \mathrm{~s}$. The tensile test is carried out on the WAW1000 type electric hydraulic servo universal testing machine. The sample raw material is cut out from $1 / 4$ to $1 / 2$ width of steel plate lengthways, and then is processed into Charpy V-notch impact specimen. The impact test is carried out on the Instron 9250HV floor-type oscillography impact testing machine, and the cooling medium is the mixture of dry ice and alcohol.

The metallographic specimen is cut out along the longitudinal direction of rolling, and is corroded by $4 \%$ nitric acid alcohol after being grinded and polished. The microstructure is investigated by LEICA $2500 \mathrm{M}$ optical microscope, FEI Quanta 600 scanning electron microscope.

\section{EXPERIMENTAL RESULTS AND ANALYSIS}

\subsection{MECHANICAL PROPERTIES AND ANALYSIS}

The microhardness values of test steel under different processes are shown in Table 2. The hardness reaches the higher wear-resisting level as HV486 under the condition of $\mathrm{CR}+\mathrm{AC}$ process. With the further increase of the cooling velocity, the hardness value reaches the maximum about HV540 with the $9^{\circ} \mathrm{C} / \mathrm{s}$ cooling velocity. However, the cooling velocity is further increased to $15^{\circ} \mathrm{C} / \mathrm{s}$, instead, the hardness decreases to HV532. Table 2 shows the 
TABLE II. TENSILE PROPERTIES WITH DIFFERENT PROCESSES

\begin{tabular}{|c|c|c|c|c|c|c|c|c|}
\hline process & $\sigma_{0.2} / \mathrm{MPa}$ & $\sigma_{\mathrm{b}} / \mathrm{MPa}$ & $\sigma_{0.2} / \sigma_{\mathrm{b}}$ & $\delta_{5} / \%$ & $\Psi / \%$ & Vickers Hardness & $\begin{array}{l}\mathrm{A}_{\mathrm{KV}} / \mathrm{J} \\
20^{\circ} \mathrm{C}\end{array}$ & $\begin{array}{l}\mathrm{A}_{\mathrm{KV}} / \mathrm{J} \\
-30^{\circ} \mathrm{C}\end{array}$ \\
\hline $\mathrm{CR}+\mathrm{AC}$ & 1032 & 1550 & 0.65 & 13.7 & 35.59 & 486 & 46 & 38 \\
\hline $\mathrm{CR}+\mathrm{CC}$ & 915 & 1640 & 0.56 & 12.78 & 35.55 & 540 & 42 & 42 \\
\hline $\mathrm{CR}+\mathrm{DQ}$ & 1020 & 1545 & 0.66 & 11.94 & 31.42 & 532 & 47 & 41 \\
\hline
\end{tabular}
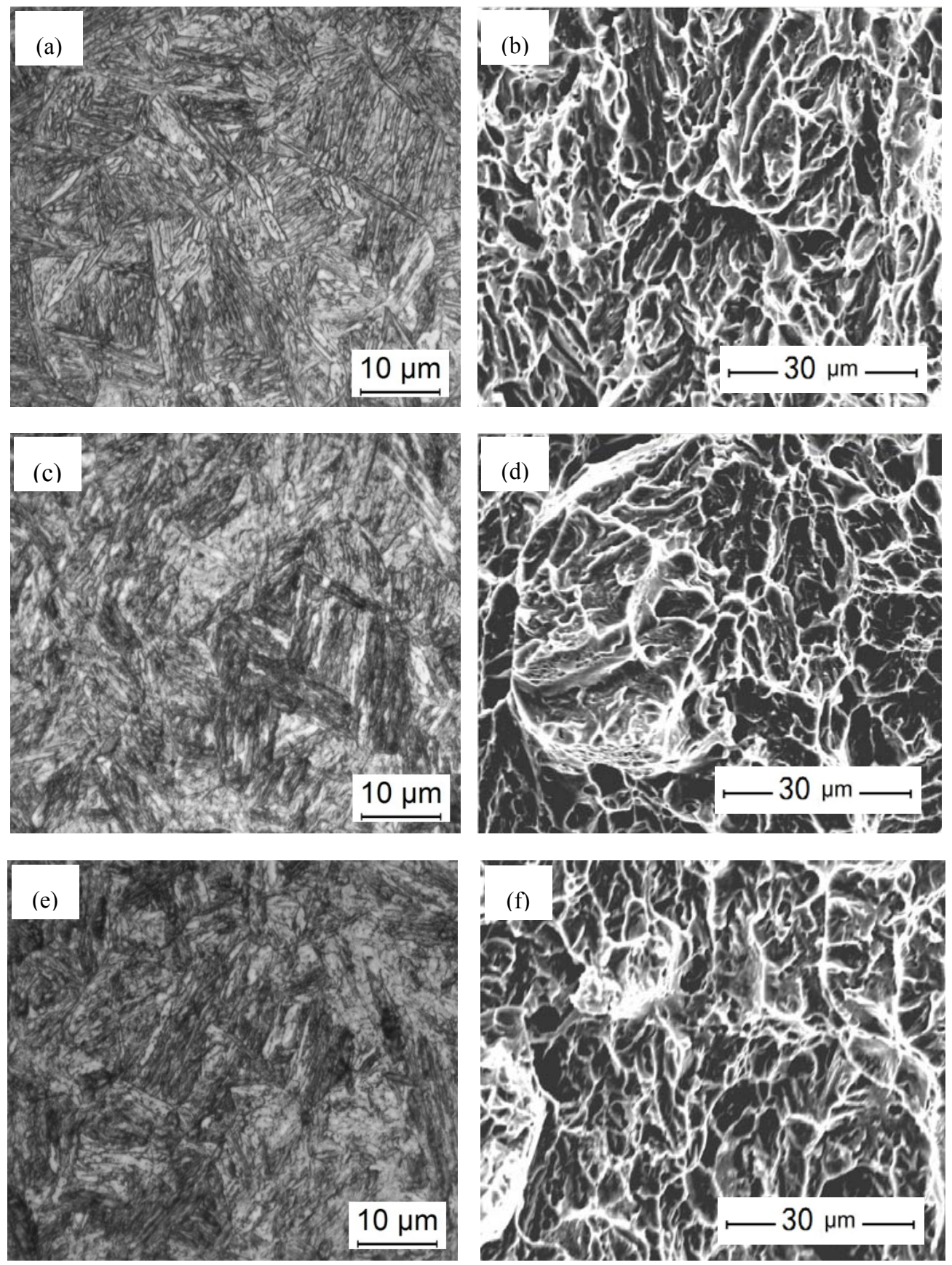

Figure 2. Optical microstructures and fractography at different process (a), (b):CR+AC; (c), (d):CR+CC; (e), (f):CR+DQ 
tensile properties of the test steel under different technologies. It is particularly obvious that with the cooling rate improvement, the tensile strength slightly increase, but the plasticity decreases obviously. The largest extensibility rate of the $\mathrm{CR}+\mathrm{AC}$ technology is $13.70 \%$ and the minimum section shrinkage rate of CR+DQ technologyis $31.42 \%$. It is thus clear that the cooling rate increases, but the steel plasticity decreases. Although the cooling rate of $\mathrm{CR}+\mathrm{CC}$ technology is less than that of $C R+D Q$ technology, because the final cooling temperature of $\mathrm{CR}+\mathrm{CC}$ technology is lower below Ms point. Martensite transforms more fully, hence there appears more martensite structure. As a result of this, the tensile strength of $\mathrm{CR}+\mathrm{CC}$ reaches $1640 \mathrm{MPa}$ which is obviously higher than that of $\mathrm{CR}+\mathrm{DQ}$.

As can be seen from Table 2, the difference of the test steel impact energy with three technologies is small. The mean value of the impact energy is between $40 \mathrm{~J}$ and $50 \mathrm{~J}$. The impact energy at $-30^{\circ} \mathrm{C}$ is slightly less than that at room temperature, which suggests that test steel has better low temperature impact toughness.

\subsection{THE STRUCTURE ANALYSIS OF TEST STEEL}

Figure 2 (a) and (b), 6(c), (d), (e) and (f) show optical microstructures and fractography with AC, CC and DQ process, respectively. It is clear from Figure 2 (a) that the structure of hot rolling test steel presents slender bamboo-like bainite ferrite lath,and bainite laths arrange crosswise in bundle with the $\mathrm{CR}+\mathrm{AC}$ technology. With the cooling rate increasing, bainite laths are further refined under the condition of $\mathrm{CR}+\mathrm{CC}$ technology. However, under the condition of $\mathrm{CR}+\mathrm{DQ}$ technology, bainitic lath presents black needle shape, and at the same time, there appears a small amount of martensite structure. It is observed that bainite and martensite laths with the $\mathrm{CR}+\mathrm{CC}$ technology are tinier than those with the $\mathrm{CR}+\mathrm{DQ}$ technology. Furthermore, lath martensite volume fraction increases, but the volume fraction of bainite decreases with the $\mathrm{CR}+\mathrm{CC}$ technology.

Figure 2(b), (d) and (f) are the fractography with -30 ${ }^{\circ} \mathrm{C}$, respectively. The dimples are well-distributed and fine equiaxed dimples by using the $\mathrm{CR}+\mathrm{AC}$ technology. The reason for the dimples of smaller size is that the fracture is ductile fracture with large nucleation density and small spacing. The dimples size is not the same, and their distribution is not even enough by using the $\mathrm{CR}+\mathrm{CC}$ technology. The fracture mechanism is compound coordinating fracture both quasi-cleavage fracture and ductile fracture. Under the CR+DQ technology, fracture is the quasi-cleavage fracture, the fracture is flat, and the dimples are less and shallower. It is not difficult to see that the impact ductility of DQ process both at $20{ }^{\circ} \mathrm{C}$ and $-30{ }^{\circ} \mathrm{C}$ is higher than other two kinds of technologies, which is attributed to the residual austenite morphology between strip bainite and lath martensite. The membrane residual austenite is more beneficial for the tenacity at room temperature than the blocky residual austenite.

\section{CONCLUSIONS}

1. The reasonable test steel ingredient can meet the production conditions of both steelmaking in ordinary iron and steel enterprises and in the rolling factories, and can produce ultra-high strength steel in batch.

2 . The Vickers hardness of steel plate reaches 486 , $\sigma_{0.2}=1032 \mathrm{Mpa}, \sigma_{\mathrm{b}}=1550 \mathrm{Mpa}, \delta 5=13.70 \%, \psi=35.59 \%$, $\sigma_{0.2} / \sigma_{b}=0.65$ by using the weak cooling technology $\mathrm{CR}+\mathrm{AC}$. With the cooling rate increasing, yield strength of the steel plate decreases to $915 \mathrm{MPa}$, the tensile strength can reach $1640 \mathrm{MPa}$ at most, and the yield ratio is 0.56 by using the $\mathrm{CR}+\mathrm{CC}$ technology.

3. The fracture mechanism is compound coordinating fracture both quasi-cleavage fracture and ductile fracture under three technologies routes, the fracture is not even, and there is a certain amount of dimples.

\section{ACKNOWLEDGEMENTS}

This paper is supported by Scientific and Technological Research Program of Chongqing Municipal Education Commission (NO.KJ1501324): "The structure regulation mechanism research of ultra high strength steel based on the economical short flow process", General project of Chongqing frontier and applied basic research project (NO. cstc2015jcyjA90005) : Effect of hydroxyl group additive on the electrolyte of vanadium batter and its action mechanism, and the research foundation of chongqing university of science \& technology (No. CK2013Z16 \& No. CK2014Z20).

\section{REFERENCES}

[1] A. J. Kaijalainen, P. Suikkanen, L. P. Karjalainen, and J. J. Jonas, "Effect of Austenite Pancaking on the Microstructure, Texture, and Bendability of an Ultrahigh-Strength Strip Steel," Metallurgical and Materials Transactions A, vol. 45, no. 3, pp. 1273-1283, 2014.

[2] X.-L. Zhao, "Section capacity of very high strength (VHS) circular tubes under compression," ThinWalled Structures, vol. 37, no. 3, pp. 223-240, 2000.

[3] G. Wang, Y. Yan, J. Li, J. Huang, Y. Su, and L. Qiao, "Hydrogen embrittlement assessment of ultra-high strength steel 30CrMnSiNi 2," Corrosion Science, vol. 77, pp. 273-280, 2013.

[4] D. Branagan, A. Frerichs, B. Meacham, L. Ma, I. Yakubtsov, S. Cheng, and A. Sergueeva, New Mechanisms, Enabling Structures, and Advanced Properties Resulting in a New Class of 3 rd Generation AHSS Sheet, SAE Technical Paper, 2014.

[5] L. Chang, and H. Bhadeshia, "Carbon content of austenite in isothermally transformed 300M steel," Materials Science and Engineering: A, vol. 184, no. 1, pp. L17-L19, 1994.

[6] S. Y. Sirin, K. Sirin, and E. Kaluc, "Effect of the ion nitriding surface hardening process on fatigue behavior of AISI 4340 steel," Materials Characterization, vol. 59, no. 4, pp. 351-358, 2008.

[7] G. Yang, X. Sun, Z. Li, X. Li, and Q. Yong, "Effects of vanadium on the microstructure and 
mechanical properties of a high strength low alloy martensite steel," Materials \& Design, vol. 50, pp. 102107, 2013.

[8] H. K. D. H. Bhadeshia, Bainite in steels: Inst. of Metals, 1992.

[9] S. Zhang, M. Li, Y. Liu, J. Luo, and T. Liu, "The growth behavior of austenite grain in the heating process of 300M steel," Materials Science and

Engineering: A, vol. 528, no. 15, pp. 4967-4972, 2011. [10] H. Hou, L. Qi, and Y. Zhao, "Effect of

austenitizing temperature on the mechanical properties of high-strength maraging steel," Materials Science and Engineering: A, vol. 587, pp. 209-212, 2013.

[11] Z. Guo, "The limit of strength and toughness of steel," Lawrence Berkeley National Laboratory, 2001.

[12] C. Zheng, D. Raabe, and D. Li, "Prediction of post-dynamic austenite-to-ferrite transformation and reverse transformation in a low-carbon steel by cellular automaton modeling," Acta Materialia, vol. 60, no. 12, pp. 4768-4779, 2012.

[13] V. Sagaradze, V. Danilchenko, P. L'Heritier, and V. Shabashov, "The structure and properties of $\mathrm{Fe}-$ $\mathrm{Ni}$ alloys with a nanocrystalline austenite formed under different conditions of $\gamma-\alpha-\gamma$ transformations," Materials Science and Engineering: A, vol. 337, no. 1, pp. 146159, 2002. 